\title{
The kinetic variations of anti-nucleocapsid antibody in SARS-CoV-2 infection
}

Shoji Kawada $\mathrm{MD}^{1}$, Atsushi Ogata MD $\mathrm{PhD}^{1,2}$, Yasuhiro Kato MD $\mathrm{PhD}^{2}$, Masashi

Okamoto $\mathrm{MD}^{1}$, Yuta Yamaguchi $\mathrm{MD}^{2}$, Takayoshi Morita $\mathrm{MD} \mathrm{Ph}^{2,3}$, and Atsushi Kumanogoh $\mathrm{MD} \mathrm{PhD}^{2,3,4}$.

${ }^{1}$ Division of Rheumatology, Department of Internal Medicine, Daini Osaka Police

Hospital, Osaka, Japan, ${ }^{2}$ Department of Respiratory Medicine and Clinical Immunology,

Osaka University Graduate School of Medicine, Osaka, Japan, ${ }^{3}$ Laboratory of

Immunopathology, World Premier International Immunology Frontier Research Center,

Suita, Osaka, Japan, ${ }^{4}$ Integrated Frontier Research for Medical Science Division, Institute for Open and Transdisciplinary Research Initiatives, Osaka University, Suita, Osaka, Japan

\section{Corresponding Author:}

Atsushi Ogata, MD, PhD, Division of Rheumatology, Department of Internal Medicine, Daini Osaka Police Hospital, Osaka Japan and Department of Respiratory Medicine and Clinical Immunology, Osaka University Graduate School of Medicine, Osaka, Japan

Phone: + 81-6-6773-7111, Fax: + 81-6-6772-2302

Email: a24ogata@icloud.com 


\section{Footnote Page}

\section{Conflicts of Interest}

AO; personal fees: Chugai, Eli Lilly, Asahi-Kasei Pharma, Daiichi Sankyo,

Bristol-Myers Squibb, Janssen, Sanofi, GlaxoSmithKline, outside the submitted work.

SK, YK, MO, YY, TM, and AK have nothing to disclose.

\section{Contributors:}

SK and AO had full access to all the data in the study and takes responsibility for the integrity of the data and the accuracy of the data analysis. Concept and design: AO and AK. Acquisition, analysis, or interpretation of data: All authors. Drafting of the manuscript: SK, AO, and AK. Administrative, technical, or material support: SK, YK, MO, YY, TM.

\section{Funding:}

This work was supported by research grants from Japan Agency for Medical Research and Development (AMED) (grant no. 18059042 and JP19ek0109307, 200705710 and JP20fk0108265, 200705079 and JP20nk0101612 to AK); Center of Innovation stream and Sports Research Innovation Project grants from the Ministry of Education, Culture, Sports, Science and Technology (MEXT) of Japan (to AK); grants from MEXT/Japan Society for the Promotion of Science (JSPS) KAKENHI (grant no. JP18H05282 to AK).

\section{Ethics approval:}

The study was approved by the local Ethics Committee of DOPH and registered in University Hospital Medical Information Network (UMIN) clinical trials registry in Japan (UMIN000040453). 


\section{Data availability statement:}

The data that support the findings of this study are available from the corresponding author upon reasonable request.

\section{Patient and public involvement:}

Patients and/or the public were not involved in the design, or conduct, or reporting or dissemination plans of this research.

\section{Acknowledgments:}

The authors would like to thank Enago (www.enago.jp) for the English language review. 


\begin{abstract}
$\underline{\text { Abstract }}$
The humoral immune response to severe acute respiratory syndrome

coronavirus 2 (SARS-CoV-2) plays a pivotal role in controlling coronavirus disease

2019 (COVID-19) infections. However, little is known about the persistence of the antibody response.

We evaluated that the kinetics of anti-nucleocapsid protein antibody of SARS-CoV2 infected healthcare workers in COVID-19 cluster occurred hospital. The long-term kinetics of anti-N antibody was classified high and keep pattern, high and decay pattern, and low and keep pattern. COVID-19 contact and symptomaticity was not related to kinetic patterns.

The reason of kinetic difference was still unclear. However natural anti-SARS-CoV-2 antibody persistence was not uniform, suggesting inter-individual difference of SARS-CoV2 vaccine efficacy.
\end{abstract}

\title{
$\underline{\text { Introduction }}$
}

The humoral immune response to severe acute respiratory syndrome coronavirus 2 (SARS-CoV-2) plays a pivotal role in controlling coronavirus disease 
2019 (COVID-19) infections. Serologic tests that measure antibodies are the preferred method for evaluating immunity to SARS-CoV-2. However, little is known about the persistence of the antibody response.

\section{$\underline{\text { Methods }}$}

A local outbreak of COVID-19 occurred between April 11 to May 11 at the

Diani-Osaka Police Hospital in Japan. During the outbreak, comprehensive

cross-sectional nucleic acid tests were performed in health care workers (HCWs) from

April 27 to May 11. Subsequent serologic surveys were performed using a

semi-quotative assay for anti-nucleocapsid (N) immunoglobulin antibodies (Roche

Diagnostics) from May 25 to June 16. Monthly follow-up serologic surveys were

conducted in seropositive individuals. Awareness of contact with COVID-19 and

related symptoms were measured using questionnaires. Anti-spike (S) antibodies

(Roche) were evaluated 7 months after diagnosis.

\section{$\underline{\text { Results }}$}


Of the 576 hospital employees, $520 \mathrm{HCWs}$ underwent nucleic acid tests and serologic tests for SARS-CoV-2. 42 HCWs were nucleic acid tested positive. During the outbreak at the hospital, the first serologic tests were performed $22.2 \pm 8.4$ days after the nucleic acid test, of which 52 were seropositive. Monthly follow-up serologic surveys were performed in 45 seropositive HCWs. The kinetics of anti-N antibodies were classified into three patterns (Figure 1). In 15 individuals, anti-N antibodies significantly increased and persisted (high-keep); in 16 individuals, anti-N antibodies increased significantly but later declined (high-decay); and in 14 individuals, anti-N antibodies increased modestly and persisted (low-keep). Furthermore, anti-N antibodies increased gradually over time in six individuals (three with the high-keep pattern and three with the low-keep pattern). Individuals with the high-keep kinetic pattern of anti-N antibodies had a higher titer of anti-S antibodies at 7 months postdiagnosis. The kinetic pattern of anti-N antibodies showed no apparent correlation with either COVID-19 contact or symptomaticity (Table 1). Seropositivity persisted in all HCWs up to 7 months after diagnosis, and there were no reinfections of COVID-19.

\section{$\underline{\text { Discussion }}$}


Most SARS-CoV-2 infected individuals display an antibody response within

21 days of infection. However, the persistence of antibodies against SARS-CoV-2

remains controversial. Some studies have reported robust antibody responses against

SASR-CoV-2 $(1,2)$, whereas others have reported declines in antibody titers $(3,4)$. In

our study, longitudinal change in anti-N antibodies was not uniform and was classified

into three patterns: high levels of anti-N antibodies were obtained and maintained

(high-keep); high levels of anti-N antibodies were obtained but declined (high-decay);

and low levels of anti-N antibodies were obtained and maintained (low-keep). Antibody

titers increased in some individuals. In our cohort, all HCWs were exposed to the

COVID-19 outbreak at the hospital simultaneously. Additional close contact to

COVID-19 was not reported in any HCWs. The antibody response was not boosted by

re-exposure to SARS-CoV-2. The cause of kinetic variation of the anti-N antibody

response was unclear but may be influenced by unknown interindividual differences in

antibody response.

Previous reports have demonstrated that severe infections exhibit a strong and

prolonged antibody response (5). Anti-S antibodies were enriched among recovering

individuals, whereas anti-N antibodies were enriched in deceased individuals (6). In our

study, disease severity was not correlated with the titer or kinetic pattern of anti-N 
antibodies. Because the nucleocapsid protein of the COVID-19 virus is not exposed to the outside the virion, anti-N antibodies respond to destroyed or incomplete virus particles but not to infectable virus particles. Therefore, anti-N antibodies may not be related to disease recovery. The variation in antibody response raises questions concerning the efficacy of the SARS-CoV-2 vaccine. A personalized approach to boost the immune response to the SARS-CoV-2 vaccine may be necessary to eradicate COVID-19.

\section{$\underline{\text { References }}$}

1. Wajnberg A, Amanat F, Firpo A, et al. Robust neutralizing antibodies to SARS-CoV-2 infection persist for months. Science. 2020; 370:1227-1230.

2. Gudbjartsson DF, Norddahl GL, Melsted P, et al. Humoral Immune Response to SARS-CoV-2 in Iceland. N Engl J Med. 2020; 383:1724-34

3. Ibarrondo FJ, Fulcher JA, Goodman-Meza D, et al. Rapid Decay of Anti-SARS-CoV-2 Antibodies in Persons with Mild Covid-19. N Engl J Med. $2020 ; 383: 1085-87$

4. Seow J, Graham C, Merrick B, et al. Longitudinal observation and decline of neutralizing antibody responses in the three months following SARS-CoV-2 infection in humans. Nat Microbiol. 2020; 5:1598-1607.

5. Long QX, Tang XJ, Shi QL, et al. Clinical and immunological assessment of asymptomatic SARS-CoV-2 infections. Nat Med. 2020; 26:1200-04. 
medRxiv preprint doi: https://doi.org/10.1101/2021.02.05.21251208; this version posted February 8, 2021. The copyright holder for this preprint (which was not certified by peer review) is the author/funder, who has granted medRxiv a license to display the preprint in perpetuity. It is made available under a CC-BY-NC-ND 4.0 International license.

6. Atyeo C, Fischinger S, Zohar T, et al. Distinct early serological signatures track with SARS-CoV-2 survival. Immunity. 2020; 53:524-532. 
Figure-1 kinetics patterns of antibody against to SARS-CoV-2 N protein

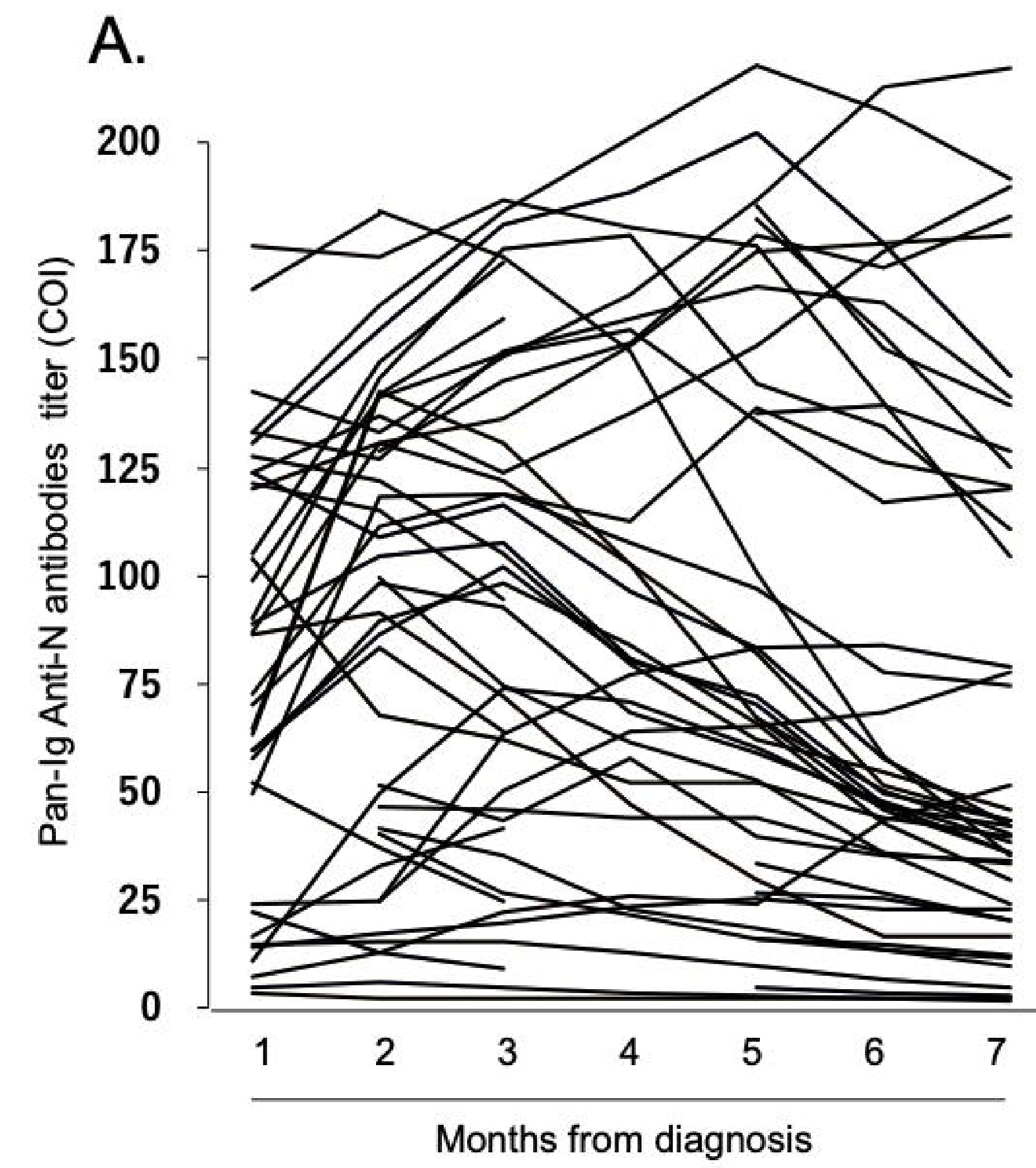

B.

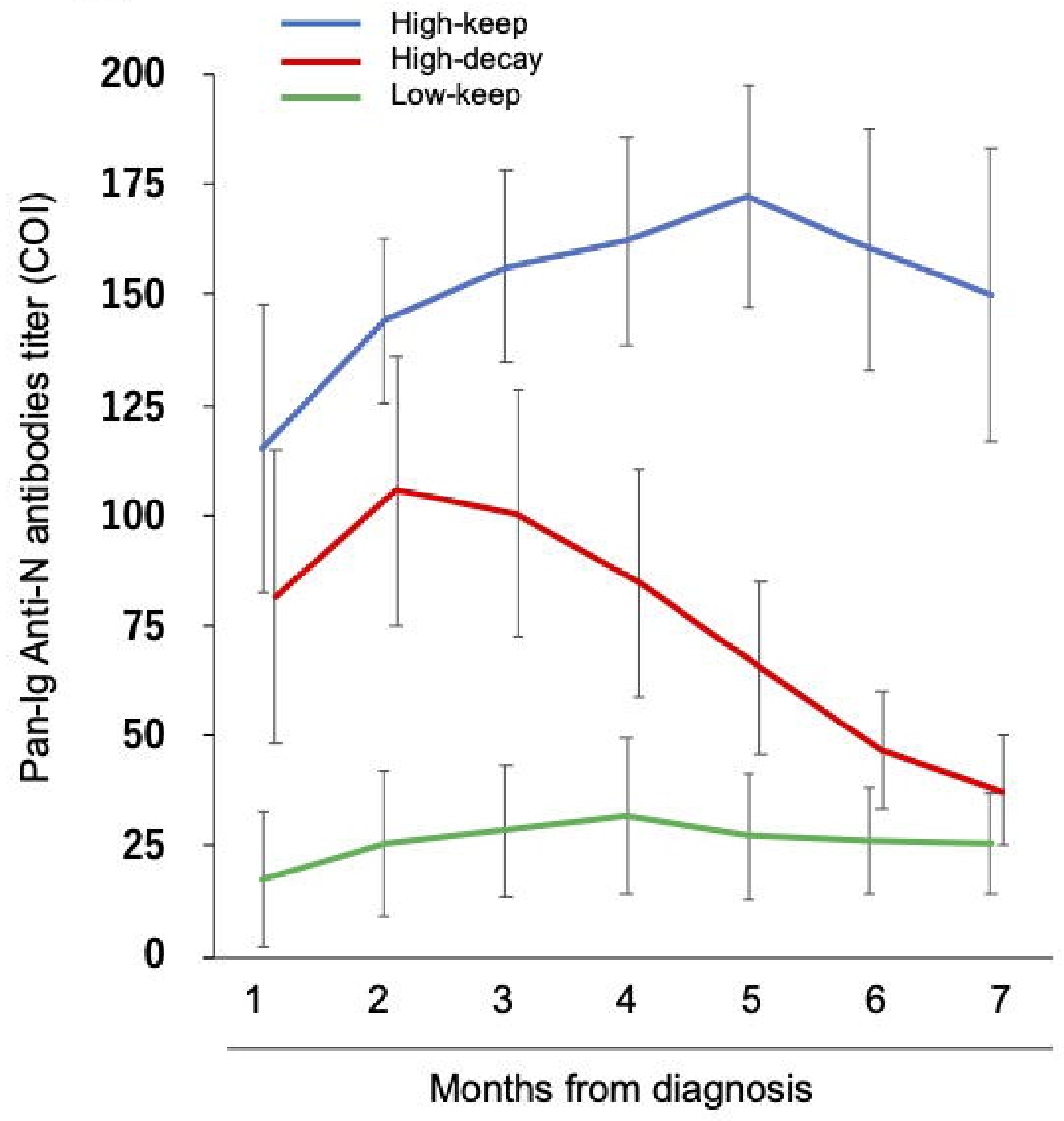


medRxiv preprint doi: https://doi.org/10.1101/2021.02.05.21251208; this version posted February 8, 2021. The copyright holder for this preprint (which was not certified by peer review) is the author/funder, who has granted medRxiv a license to display the preprint in perpetuity.

\section{It is made available under a CC-BY-NC-ND 4.0 International license.}

\begin{tabular}{|c|c|c|c|c|}
\hline \multicolumn{2}{|c|}{ Pattern } & High-keep & High-decay & Low-keep \\
\hline \multicolumn{2}{|l|}{$\mathrm{N}$} & 15 & 16 & 14 \\
\hline \multicolumn{2}{|l|}{$\operatorname{PCR}(+)$} & $14(93 \%)$ & $14(88 \%)$ & $13(93 \%)$ \\
\hline \multicolumn{2}{|l|}{ Age } & $39.6 \pm 11.5$ & $34.2 \pm 10.9$ & $40.2 \pm 10.8$ \\
\hline \multicolumn{2}{|l|}{$\operatorname{Sex}(M ; F)$} & $0 ; 15$ & $2 ; 14$ & $2 ; 13$ \\
\hline \multicolumn{5}{|c|}{ Final anti-S Antibody } \\
\hline \multirow{3}{*}{ contact } & closed & $12(80 \%)$ & $10(63 \%)$ & $8(57 \%)$ \\
\hline & Non-closed & $2(13 \%)$ & $5(31 \%)$ & $5(36 \%)$ \\
\hline & No awareness & $1(7 \%)$ & $1(6 \%)$ & $1(7 \%)$ \\
\hline \multirow{8}{*}{ symptoms } & no & $2(13 \%)$ & $5(31 \%)$ & $2(14 \%)$ \\
\hline & fever & $12(80 \%)$ & $9(56 \%)$ & $10(71 \%)$ \\
\hline & Rhinitis & $4(27 \%)$ & $4(25 \%)$ & $6(43 \%)$ \\
\hline & Cough & $8(53 \%)$ & $3(19 \%)$ & $7(50 \%)$ \\
\hline & fatigue & $9(60 \%)$ & $7(44 \%)$ & $11(79 \%)$ \\
\hline & dysgeusia & $6(40 \%)$ & $5(31 \%)$ & $4(29 \%)$ \\
\hline & GI symptoms & $4(27 \%)$ & $3(19 \%)$ & $2(14 \%)$ \\
\hline & headache & $4(27 \%)$ & $2(13 \%)$ & $4(29 \%)$ \\
\hline \multicolumn{2}{|c|}{ Anti-S antibody ( $7^{\text {th }}$ Month) } & $452.4 \pm 817.5$ & $217.2 \pm 318.1$ & $176.4 \pm 103.0$ \\
\hline
\end{tabular}

